\title{
Prevalence and Patterns of Child Sexual Abuse in Selected Countries of Asia and Africa: A Review of Literature
}

\author{
Victor Selengia ${ }^{1}$, Hanh Nguyen Thi Thuy², Declare Mushi ${ }^{3}$ \\ ${ }^{1}$ Directorate of Research and Consultancy, Kilimanjaro Christian Medical University College, Moshi, Tanzania \\ ${ }^{2}$ The Department of Population and Reproductive Health, Institute for Preventive Medicine and Public Health, Hanoi Medical \\ University, Hanoi, Vietnam \\ ${ }^{3}$ Institute of Public Health, Kilimanjaro Christian Medical University College, Moshi, Tanzania \\ Email: victor.selengia@kcmuco.ac.tz
}

How to cite this paper: Selengia, V., Thuy, H. N. T., \& Mushi, D. (2020). Prevalence and Patterns of Child Sexual Abuse in Selected Countries of Asia and Africa: A Review of Literature. Open Journal of Social Sciences, 8, 146-160. https://doi.org/10.4236/jss.2020.89010

Received: June 23, 2020

Accepted: September 14, 2020

Published: September 17, 2020

Copyright $\odot 2020$ by author(s) and Scientific Research Publishing Inc. This work is licensed under the Creative Commons Attribution International License (CC BY 4.0).

http://creativecommons.org/licenses/by/4.0/

(c) (i) Open Access

\begin{abstract}
Africa and Asia are among the regions with the highest rates of child sexual abuse (CSA) in the world. They also share the highest proportion of children under 18 with Asia alone accounting for $24 \%$ of children under 14 years of age and about $41 \%$ of the African population are under the age of 15 . Despite the magnitude of the problem, few studies have investigated CSA in these regions hence limiting appropriate and timely response. Objectives: To describe the prevalence and patterns of child sexual abuse in Africa and Asia. Methods: This was a literature review study. Electronic database search was performed to select relevant materials on CSA published between 2000 and 2018. Electronic search articles were included in the review after screening for inclusion and exclusion criteria. Results: The study showed prevalence of CSA (broadly and narrowly defined) in Africa to be from $2.1 \%-68.7 \%$ for females in Tanzania and Ethiopia and $4.1 \%-60 \%$ for males in South Africa. The prevalence in Asia ranges from 3.3\% - 42.7\% for females in China and India respectively and $4.3 \%-58 \%$ for males in Hong Kong and Sri Lanka. The rates for contact CSA among females in Asia are from 1.9\% - 59.2\% in China and India and $1.8 \%-9.1 \%$ for males in China while for non-contact abuse ranges from $1.8 \%-28.7 \%$ for females in China and India and 3.1\% 29.4\% for males in China. The findings in both regions suggest high risk of victimization in pre-pubertal and late adolescent, however, pre-pubertal victimization is much higher in Africa. Victim's home and public area found to be high risk places for abuse in both regions. Relatives comprise common perpetrators in Asia while friends were most cited in Africa. Conclusions: The results highlight high rate of CSA in Africa and Asia calling for comprehensive approach for its prevention. Future research should focus more on
\end{abstract}


population-based studies and using comparable methodology.

\section{Keywords}

Africa, Asia, Children, Prevalence, Sexual Abuse

\section{Introduction}

Child sexual abuse (CSA) has been categorized by different researchers across the world as representing a global human rights violation of vast proportions with severe immediate and long-term health and social consequences (Hillis et al., 2016). The World Health Organization (WHO) "World Report on Violence and Health" (2002) and the United Nations (UN) "UN Secretary General's Study on Violence Against Children" (2006) have both reported the existence of an alarming number of children across the globe who are sexually abused every year. According to WHO 2006, about $20 \%$ of women and $8 \%$ of men in 39 countries worldwide were reported to have been sexually abused as children (Chan et al., 2013). Current data suggests that approximately $4 \%$ of girls and $2 \%$ of boys experience some forms of sexual abuse each year (Martin and Silverstone, 2013). Child sexual abuse may take various forms from physical contact to non-physical contact sexual abuse including; sexual harassment, touching, incest, rape or exploitation in prostitution or pornography, exposure to pornographic materials and exposure to one's private parts. The abuse of children can happen in a variety of settings and locations including in the homes, schools, on the road, fields, care and justice institutions and public open spaces. It is also evident that CSA occurs in all ages and in all social-economic classes (Singh et al., 2014). Notably, the children experience abuse behaviours in silence and often not realizing that they are being victimized (Fernando and Karunasekera, 2009). Various studies have found devastating association between experiences of CSA and major physical and mental health problems making it one of the important public health, social and human rights concerns in the world today (Finkelhor, 1994; Pereda et al., 2009; Stoltenborgh et al., 2011). It is estimated that CSA alone is accountable for about $1 \%$ of the global burden of disease and since it is significantly associated with other conditions such as alcohol consumption, drug use, mental disorders, and spread of sexually transmitted diseases, which when pooled, are accountable for over $20 \%$ of the global burden of disease (Singh et al., 2014). The consequences of CSA in low-and middle-income countries including Africa and Asia are even more devastating. A study on economic burden of child maltreatment (inclusive of sexual abuse) in the Asia Pacific region indicates that the burden of disease attributable to child maltreatment is costing the region of about $1 \%$ and 3\% of national GDP per annum (Fang et al., 2015). A systematic review of 55 studies from 24 countries found the rates of CSA to be between $8 \%$ and $31 \%$ for females and $3 \%$ and $17 \%$ for males (Barth et al., 2013). The same study found nine girls and 3 boys out of 100 have experienced forced 
penetration. It is also reported that the chances of experiencing sexual victimization are high during pre-pubertal period and peak in adolescence (Martin and Silverstone, 2013). Despite the consequences and magnitude of the problem, data suggests that over $95 \%$ of cases of CSA are never disclosed to authorities (Martin and Silverstone, 2013). Majority of studies in CSA have been conducted in the western world largely in North America, Western Europe and Australasia with relatively very few in Africa and Asia (Jirapramukpitak et al., 2005; Kenny and McEachern, 2000). The aim of the present paper therefore was to investigate the situation of CSA in Africa and Asia by reviewing relevant studies reporting on the topic over the period of eighteen years (2000-2018) and describing important patterns to enable comprehensive understanding of the characteristics of CSA.

\section{Methods}

Studies that met the following criteria were included: 1) studies reporting prevalence of CSA with exposure age 18 years and below in Africa and Asia (with emphasis on sub-Saharan Africa, South East Asia and Asia Pacific region) 2) non-clinical samples (with exception of a study in a war-torn Democratic Republic of Congo (DRC) and a hospital-based study in Zimbabwe) 3) articles published in English language and 4) articles published between January 2000 and December 2018. The inclusion of two hospital-samples in the DRC and Zimbabwe is mainly due to paucity of studies in the region. For DRC the region is affected by armed-conflicts for a long time a situation which limits a conducive environment for conducting research and in particular on sensitive topic as CSA. The only convenient site to gather possible evidence of CSA is within hospitals and special clinics for post-sexual violence care to the victims of CSA.

\section{Search Strategy}

Electronic search engines including PubMed, Google scholar and Cochrane reviews database were used to search materials published between 2000 and 2018 by combining the MeSh terms "Child Abuse, Sexual" AND "Asia" AND "epidemiology" OR "prevalence" AND "Africa". The last search was performed in June 27, 2019. In addition, manual search for relevant articles, scientific papers and reports was also performed including searches from specific country's Demographic and Health Survey reports, United Nations, WHO, UNICEF, CDC and findings from other trusted local and international NGOs. Reference lists of relevant articles were also consulted to generate additional relevant materials. Figure 1 provides a description of the article selection process.

\section{Outcome measures}

The main described outcome measures were overall prevalence of CSA, prevalence of specific contact and non-contact CSA, prevalence rates in specific age cohorts, victim-perpetrator relationship, gender and common location for abuse and characteristics of the study (Author, country, and method of data collection, age of exposure, sample size, response rate, sampling method, setting, definition, and prevalence). 


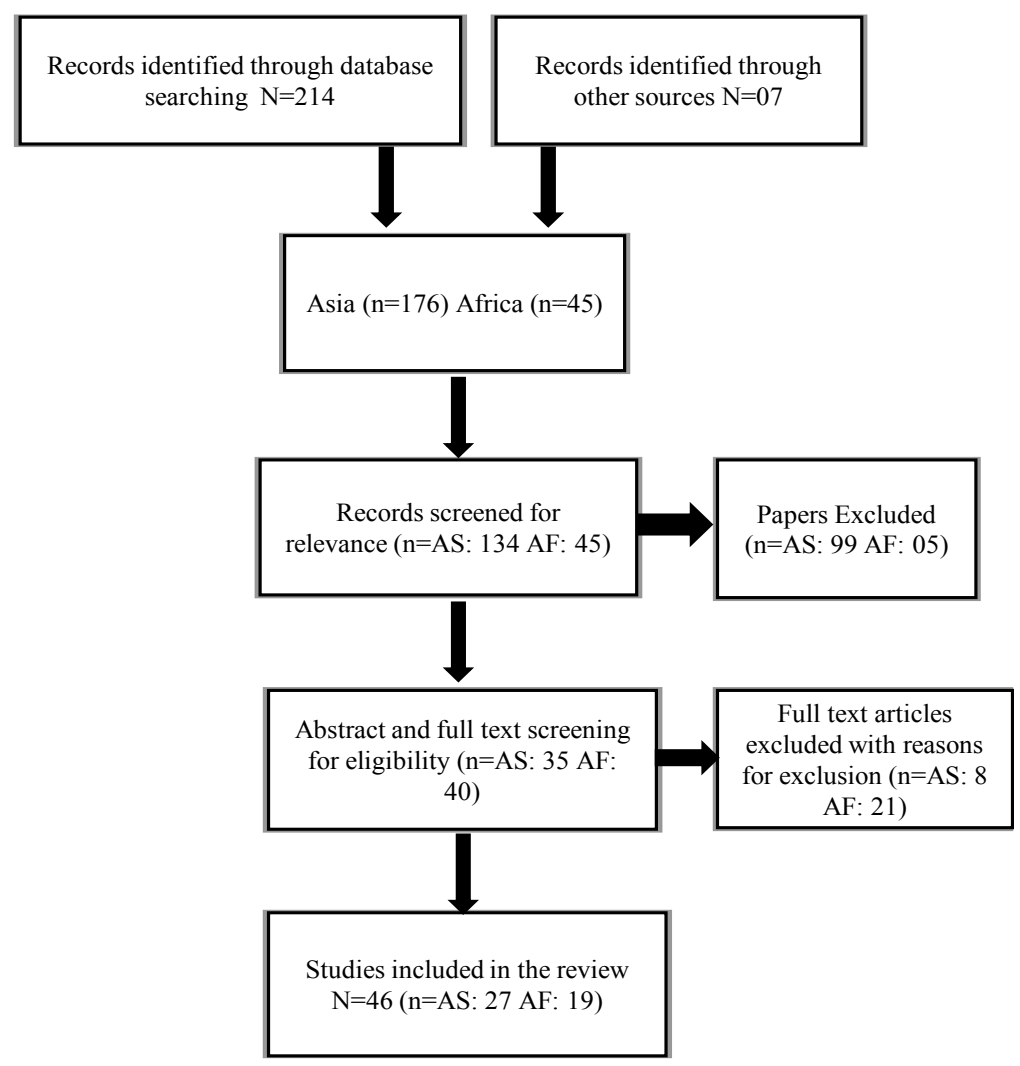

Figure 1. Article selection process.

\section{Results}

\section{Characteristics of the studies}

The preliminary search generated a total of 214 papers (174 from Asia and 40 from Africa), plus additional seven studies from respective country's nationally representative surveys and studies from International Organizations. After screening for inclusion and exclusion criteria, a final number of 46 papers (27 from Asia and 19 from Africa) were included in the analysis. Twenty-two studies included in this review adopted anonymous self-report method (17 from Asia and 5 from Africa) while 18 studies applied face-to-face interviews (14: Africa and 4: Asia) and six systematic reviews and meta-analysis (all from Asia). Of the studies included, twenty-one measured only physical contact CSA (narrow definition of CSA; 5 Asia and 16 Africa) while 18 studies measured both physical contact and non-physical contact CSA (broad definition of CSA; 15 from Asia and 3 from Africa), none measured specifically non-physical contact CSA. Six studies reported prevalence of CSA using only female samples (2 from Asia and 4 from Africa) while 1 paper in Africa reported prevalence for only male sample. Majority of studies in both regions used less than 18 years as an age of exposure to measure prevalence of CSA while four studies used 14 years and below (with one reporting $<12$ years). Twenty two studies surveyed general population ( 7 from Asia and 15 from Africa) while 18 studies surveyed students in schools and universities (14: Asia 4: Africa). One study in Asia investigated only incest CSA 
and two studies one in both regions investigated penetrative sexual abuse while one study in Africa examined rape experiences. Some of the studies included had some missing data either the prevalence distribution by gender, method of data collection, age of exposure used, sample size, study setting or type of CSA measured. The reason being that only abstracts could be accessed therefore a full text was not screened or the specific details were not reported. Table 1 and Table 2 provide a summary of the characteristics of all studies included in this review.

Table 1. Characteristics of the included studies on the prevalence of child sexual abuse in Asia.

\begin{tabular}{|c|c|c|c|c|c|c|c|c|c|c|c|}
\hline Author (Year) & $\begin{array}{l}\hat{E} \\
\text { 苛 }\end{array}$ & 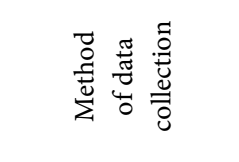 & 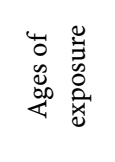 & 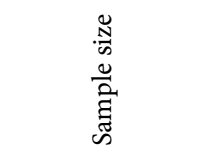 & 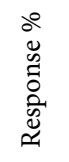 & 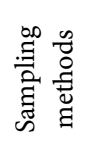 & 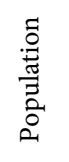 & 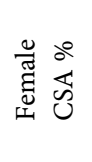 & 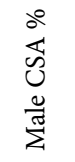 & 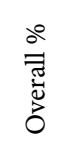 & 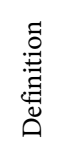 \\
\hline Luo et al., 2008 & China & Q & $<14$ & $2994(20-64)$ & 76 & $\mathrm{P}$ & G & 3.3 & 5.1 & 4.2 & $\mathrm{~N}$ \\
\hline Sun et al., 2008 & China & Q & NR & $1351(\mathrm{M}=19.8)$ & 96.7 & $\mathrm{P}$ & S & 22.1 & 14.7 & 18.4 & B \\
\hline Lin et al., 2011 & China & Q & $<16$ & $683(8-18)$ & NR & NR & G & 14.2 & 21.5 & 18 & B \\
\hline Zhao et al., 2011 & China & Q & $<16$ & $1019(6-18)$ & NA & NP & S & 24 & 37 & 30 & B \\
\hline Chan et al., 2013 & China & Q & NR & 18341 & $\mathrm{NR}$ & $\mathrm{P}$ & S & 6.4 & 8.0 & 7.2 & B \\
\hline Ji et al., 2013 & China & Meta-analysis & $<18$ & NA & NA & NA & S & 15.3 & NA & 15.3 & B \\
\hline Fang et al., 2015 & China & SR & $<18$ & 68 articles & NA & NA & NA & 9.5 & 8.0 & 8.7 & NA \\
\hline Ma, 2018 & China & Meta-analysis & $<18$ & 36 articles & $\mathrm{NA}$ & NA & NA & 8.9 & 9.1 & 9 & B \\
\hline Fu et al., 2018 & China & SR \& Meta-analysis & $<18$ & 32 articles & NA & NA & NA & NR & NR & 15.7 & B \\
\hline Tang, 2002 & Hong Kong & Q & $<17$ & 2147 & $\mathrm{NR}$ & NP & S & 7.4 & 4.3 & 6 & B \\
\hline Pan, 2007 & Taiwan & I & NR & 336 & $\mathrm{NR}$ & NR & & NR & NR & 5.4 & NA \\
\hline Yen et al., 2008 & Taiwan & Q & NR & 1684 & $\mathrm{NR}$ & NR & S & NR & $\mathrm{NR}$ & 2.5 & NA \\
\hline Fang et al., 2015 & Taiwan & Q & NR & $5276(12-18)$ & 99.4 & NR & S & NR & NR & 19.8 & NA \\
\hline Kim and Kim, 2005 & South Korea & Q & NR & 1672 & $\mathrm{NR}$ & NR & S & NR & $\mathrm{NR}$ & 3.7 & A \\
\hline $\begin{array}{l}\text { Jirapramukpitak et al., } \\
2005\end{array}$ & Thailand & Q & $<16$ & $202(16-25)$ & NR & NR & G & 6.5 & 4.9 & NR & B \\
\hline $\begin{array}{l}\text { MWCD, Government } \\
\text { of India, } 2007\end{array}$ & India & I & Lifetime & 17.220 & NA & $\mathrm{P}$ & G & 42.7 & 57.3 & 53.2 & $\mathrm{~B}$ \\
\hline Singh et al., 2014 & India & SR & $<18$ & NA & NA & NA & NA & 42 & NA & NA & B \\
\hline Tomori et al., 2016 & India & Q & $<16$ & $11,788(18 \&>)$ & NA & NP & G & NA & NA & 22.4 & $\mathrm{~N}$ \\
\hline Kumar et al., 2017 & India & Q & Lifetime & 6682 & NA & $\mathrm{P}$ & S & 8.8 & 32.5 & 23.8 & B \\
\hline Choudhry et al., 2018 & India & SR & $<18$ & NA & NA & NA & NA & $4-41$ & $4-57$ & NR & B \\
\hline Nguyen et al., 2010 & Vietnam & Q & $<18$ & $2591(12-18)$ & 94.7 & $\mathrm{P}$ & S & 18.5 & 21 & 19.8 & B \\
\hline Sumner et al., 2016 & Cambodia & I & $<18$ & $1255(13-24)$ & 89.9 & $\mathrm{P}$ & G & 4.4 & 5.6 & NR & $\mathrm{N}$ \\
\hline UNICEF, 2018a & Lao & I & $<18$ & NR & $\mathrm{NR}$ & $\mathrm{P}$ & G & 7 & 12 & NR & $\mathrm{N}$ \\
\hline Miles, 2000 & Sri Lanka & Q & NR & $145(13-17)$ & & $\mathrm{P}$ & S & NR & NR & 10 & $\mathrm{~N}$ \\
\hline $\begin{array}{c}\text { Fernando \& } \\
\text { Karunasekera, } 2009\end{array}$ & Sri Lanka & Q & $<18$ & $1322(\mathrm{M}=21.8)$ & 90 & $\mathrm{P}$ & $S$ & 34 & 58 & 44 & B \\
\hline Pereda et al., 2009 & Sri Lanka & Q & NR & $2389(\mathrm{M}=18)$ & $\mathrm{NR}$ & $\mathrm{P}$ & S & NR & NR & 14 & NR \\
\hline Choo et al., 2011 & Malaysia & Q & NR & $1870(15-17)$ & 80.5 & $\mathrm{P}$ & S & 3.7 & 5.6 & 9.3 & B \\
\hline
\end{tabular}

Method of data collection: Q (Self-report Questionnaire); I (Face-to-face-Interview); Population: G (general); S (students); Sampling: NP (non-probabilistic); P (probabilistic); definition: B (Broad); N (Narrow—only contact sexual abuse); NA (not applicable); NR (data not reported or could not be accessed). 
Table 2. Characteristics of the included studies on prevalence of child sexual abuse in Africa.

\begin{tabular}{|c|c|c|c|c|c|c|c|c|c|c|c|}
\hline Author (Year) & $\begin{array}{l}\text { E } \\
0 \\
0\end{array}$ & 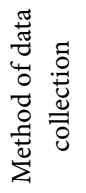 & 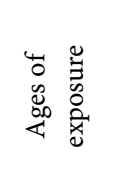 & 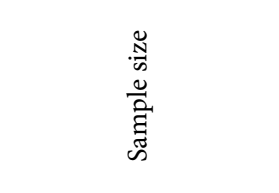 & 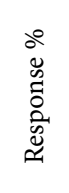 & 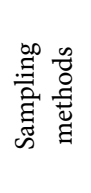 & 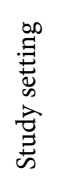 & 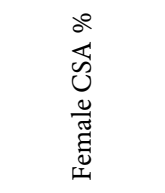 & 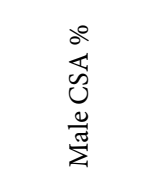 & $\frac{\partial 0}{\bar{\pi}}$ & 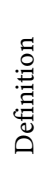 \\
\hline Sumner et al., 2016 & Kenya & I & $<18$ & $1456(13-24)$ & 80.4 & $\mathrm{P}$ & $\mathrm{G}$ & NA & 14.8 & NA & $\mathrm{N}$ \\
\hline McCrann et al., 2006 & Tanzania & Q & $<18$ & 487 & $>90$ & $\mathrm{NP}$ & S & 31 & 25 & 27.7 & B \\
\hline Richter et al., 2004 & Tanzania & I & $<12$ & 3073 & 93.6 & $\mathrm{P}$ & G & 2.1 & 4.2 & NR & $\mathrm{N}$ \\
\hline UNICEF, 2009 & Tanzania & I & $<18$ & 3790 households & $\mathrm{NR}$ & $\mathrm{P}$ & $\mathrm{G}$ & 27 & 11 & NR & $\mathrm{N}$ \\
\hline UNICEF, 2018b & Uganda & I & lifetime & $5804(18-24)$ & 82.2 & $\mathrm{P}$ & $\mathrm{G}$ & 35.3 & 16.5 & NR & $\mathrm{N}$ \\
\hline UNICEF, 2013 & Malawi & I & $<18$ & & NR & $\mathrm{P}$ & $\mathrm{G}$ & 22 & 15 & NR & $\mathrm{N}$ \\
\hline Worku et al., 2006 & Ethiopia & Q & NR & 323 & $\mathrm{NR}$ & $\mathrm{P}$ & S & - & - & 68.7 & B \\
\hline Olley, 2008 & Nigeria & Q & lifetime & $841(16-25)$ & NR & NP & S & Nf $9.4 \mathrm{f}(4.4)$ & $\mathrm{Nf} 7.2 \mathrm{f}(5.6)$ & 16.7 & $\mathrm{~N}$ \\
\hline Kunnuji \& Esiet, 2015 & Nigeria & I & $<18$ & $480(10-19) M=16$ & NR & $\mathrm{NP}$ & $\mathrm{G}$ & 18 & NR & NR & $\mathrm{N}$ \\
\hline David et al., 2018 & Nigeria & I & lifetime & $398(10-19) M=15.6$ & NR & $\mathrm{P}$ & $\mathrm{G}$ & 26 & 24.3 & 25.7 & B \\
\hline Madu \& Peltzer, 2001 & South Africa & $\mathrm{Q}$ & $<17$ & $414(\mathrm{M}=18.5)$ & NR & NP & S & 53.2 & 60 & 54.2 & $\mathrm{~N}$ \\
\hline Ward et al., 2018 & South Africa & I & lifetime & $5631(15-17)$ & 94.6 & $\mathrm{P}$ & G & 14.6 & 9.99 & 12.3 & $\mathrm{~N}$ \\
\hline Richter et al., 2014 & South Africa & I & $<12$ & $5259(18-32)$ & 84.5 & $\mathrm{P}$ & $\mathrm{G}$ & 4.9 & 4.1 & $\mathrm{NR}$ & $\mathrm{N}$ \\
\hline Reza et al., 2009 & Swaziland & Q & $<18$ & $1244(13-24)$ & 96.3 & $\mathrm{P}$ & $\mathrm{G}$ & 33.2 & NR & NR & $\mathrm{N}$ \\
\hline UNICEF, 2007 & Swaziland & I & $<18$ & 1920 households & NR & $\mathrm{P}$ & $\mathrm{G}$ & 38 & NR & NR & $\mathrm{N}$ \\
\hline Richter et al., 2014 & Zimbabwe & I & $<12$ & $2874(18-32)$ & 84 & $\mathrm{P}$ & $\mathrm{G}$ & 4.4 & 4.5 & NR & $\mathrm{N}$ \\
\hline $\begin{array}{l}\text { Zimbabwe National } \\
\text { Statistics Agency, } 2011\end{array}$ & Zimbabwe & I & $<18$ & 7797 households & $>90$ & $\mathrm{P}$ & G & 32.5 & 8.9 & NR & $\mathrm{N}$ \\
\hline Birdthistle e al., 2011 & Zimbabwe & I & $<16$ & 1194 & NR & NP & $\mathrm{G}$ & 9.1 & NR & NR & a \\
\hline Nelson et al., 2011 & DRC & I & $<18$ & 389 & NR & NP & G & 19.5 & NR & NR & c \\
\hline
\end{tabular}

Method of data collection: Q (Self-report Questionnaire); I (Face-to-face-Interview); Population: G (general); S (students); Sampling: NP (non-probabilistic); P (probabilistic); definition: B (Broad); N (Narrow—only contact sexual abuse); NR (data not reported or could not be accessed). a-dry intercourse; $\mathrm{c}-$ rape only; $\mathrm{Nf}$-abuse by non-family members; $\mathrm{f}$-abuse by family members; NBSLEA-National Baseline Survey on Life Experiences of Adolescents Report.

\section{Prevalence of child sexual abuse by gender}

Table 1 and Table 2 present prevalence of any type of CSA both gender in Asia and Africa. The results showed a wide variation in the prevalence rates of CSA across studies. The prevalence of any form of CSA in Asia ranges between $3.3 \%-42.7 \%$ for females in China and India and $4.3 \%$ - 58\% for males in Hong Kong and Sri Lanka respectively. The rates for only physical contact CSA in female samples range from $1.9 \%-59.2 \%$ in China and India respectively and $1.8 \%$ - 9.1\% for males in China. The prevalence for non-contact abuse ranges between $1.8 \%-28.7 \%$ for females in China and India and 3.1\% - 29.4\% for males in China. The prevalence of CSA in Africa ranges between 2.1\% - 68.7\% for females in Tanzania and Ethiopia respectively and $4.1 \%-60 \%$ for males in South Africa. The rates for penetrative sexual abuse for Asia ranges between $0.3 \%-3.6 \%$ for males in Cambodia and China respectively and $0.6 \%-57.1 \%$ for females in In- 
dia. Prevalence of penetrative abuse in Africa ranges between $4.9 \%$ - 56\% for females in Swaziland and Nigeria respectively and 3.5\% - 54\% for males in Kenya and Nigeria respectively. Experience of most severe forms of CSA has been observed in Africa including anal penetration and gang rape. A study in Tanzania in 2006 found $2.2 \%$ of females and $4.6 \%$ of males to have suffered anal penetration (McCrann et al., 2006). In the specialized clinics for post-sexual violence care in Harare Zimbabwe $60 \%$ of male victims reported forced anal penetration while in a war-torn DRC $12.3 \%$ of girl victims experienced gang rape.

\section{Victim's age, relationship to the perpetrator and location of abuse}

The prevalence of CSA varies across a spectrum of different age cohorts in both Asia and Africa. The risk for victimization was almost evenly spread across pre-pubertal period, early adolescence and late adolescence. However, slightly higher rates of pre-pubertal victimization were observed among studies in Africa with some studies reporting to up to $60 \%$ of children being sexually abused before they had reached their teenage (Birdthistle et al., 2011). Just over 16\% of children in Nigeria experienced their first incidence of CSA between the ages of 5 and 8 years and about 45\% between 9 and 12 years of age (David et al., 2018), while $14 \%$ of male victims in Kenya reported to have experienced their first episode of CSA when they were 10 years and below (Sumner et al., 2016). The rates for mid and late adolescents were equally devastating. A higher prevalence was reported among girls in their early and late adolescence in Swaziland with just over $88 \%$ reported victimization between 13 - 17 years of age (Reza et al., 2009).

Studies in Asia have also reported significant rates of CSA among children below 12 years of age. A study in Cambodia (Sumner et al., 2016) showed that $59.1 \%$ of male victims reported to have experienced their first episode of CSA when they were 10 years or below. Another study in India reported $40 \%$ of victims experienced first incidence of CSA between the ages of 5 and 12 years (Ministry of Women and Child Development, Government of India, 2007). Two percent of Chinese females and $1.6 \%$ of males experienced contact sexual abuse between the ages of 2 - 11 (Luo et al., 2008) and just over 1\% of females and 3\% of males experienced contact sexual abuse between the ages of 12 - 13. Fifty four percent of males in China reported to have experienced their first incidence of CSA between the ages of 12 - 16 (Sun et al., 2008). While $59.3 \%$ and $78 \%$ of victims in India and Lao respectively experienced CSA at 13 years and above.

Similar pattern of perpetrators of sexual abuse was observed in both Asia and Africa in which majority of perpetrators were well known to the child. Relatives, boyfriends and neighbors or acquaintances are cited as the most common perpetrators in Asia. A study in India showed about, 70\% and 75\% of children said relatives were responsible for unwanted fondling and forced sexual intercourse respectively (Daral et al., 2016) while a friend and neighbor accounted for $24 \%$ and 5\% respectively. Vietnam and Hong Kong reported strangers as the most common perpetrators of unwanted sexual penetration $(29.5 \%)$ and any form of CSA (28\%) respectively. In Africa, friends were most cited followed by acquaintances or neighbors and relatives. Friends were reported in Kenya (38.2\%), 
Zimbabwe (42.3\%), Nigeria (43\%), and South Africa (61.3\%) while family members or relatives were reported in Kenya (10.7\%), Zimbabwe (18\%), Nigeria (10\%) and Swaziland (14\%). Notably, teachers, doctors, solders and other person of authority were also cited in 3 studies as among common perpetrators.

In both regions, the location of abuse was spread among home, school, perpetrator's home, public/open spaces and at special events. Majority of studies in Asia and Africa indicate victim's home to be the most common place of abuse followed by outdoors or public spaces and in school. However, a study in India, 2016 has reported that most of the abuse has taken place when the victim was involved on a travel or journey (80.6\%) followed by $31.2 \%$ during marriage events or other functions. Table 3 and Table 4 provide a summary of different characteristics associated with CSA and proportion of victims at certain age respectively as reported in different studies in Asia and Africa.

Table 3. Characteristics of child sexual abuse as reported in various studies in Asia and Africa.

\begin{tabular}{|c|c|c|c|c|c|c|c|c|c|c|c|c|}
\hline \multirow[t]{2}{*}{ Characteristics } & \multicolumn{5}{|c|}{ Asia } & \multicolumn{7}{|c|}{ Africa } \\
\hline & 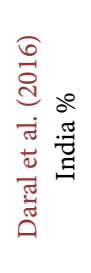 & 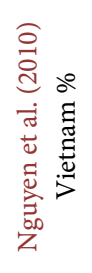 & 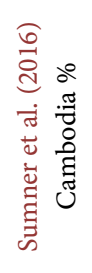 & 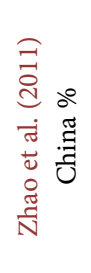 & 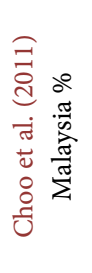 & 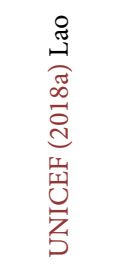 & 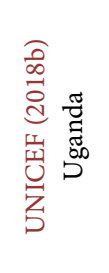 & 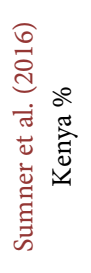 & 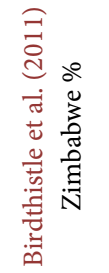 & 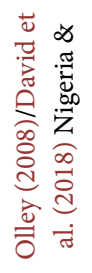 & 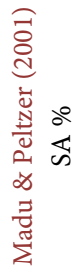 & 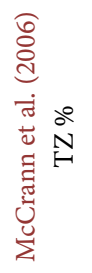 \\
\hline \multicolumn{13}{|l|}{ Age at first episode } \\
\hline$\leq 13$ years & 28.9 & - & 59.1 & - & - & 22 & 25.0 & 13.7 & 60 & 45.2 & - & 10.2 \\
\hline$>13$ years & 59.3 & - & - & - & - & 78 & - & - & - & 17.2 & - & - \\
\hline \multicolumn{13}{|l|}{ Perpetrator } \\
\hline Family member/relative & 75 & 12.5 & 37 & - & 14.8 & $\begin{array}{c}\text { F: } 0 \\
\text { M: } 35\end{array}$ & - & 10.7 & 18 & 10.0 & 6.2 & 7.2 \\
\hline Friend/acquaintance/neighbour & 25 & 14.3 & 58.2 & - & 22.7 & $\begin{array}{l}\text { F: } 38 \\
\text { M: } 42\end{array}$ & $\begin{array}{l}\text { F: } 27.9 \\
\text { M: } 23.4\end{array}$ & 38.2 & 60.1 & 43 & 61.5 & 27.9 \\
\hline Stranger & - & 29.5 & 0 & - & 4.8 & F: $8 \mathrm{M}: 8$ & F: 20.4 & 11.7 & 9.2 & 15 & 7.7 & 0.4 \\
\hline \multicolumn{13}{|l|}{ Location } \\
\hline Victim's home & - & - & 41.9 & - & - & $\begin{array}{l}\text { F: } 44 \\
\text { M: } 51\end{array}$ & $\begin{array}{l}\text { F: } 34.7 \\
\text { M: } 22.4\end{array}$ & 26.9 & 31.6 & 24.7 & - & - \\
\hline Perpetrator's home & - & - & 6.1 & - & - & $\begin{array}{l}\text { F: } 26 \\
\text { M: } 11\end{array}$ & & 7.7 & 14.9 & 23.7 & - & - \\
\hline Outdoors & - & - & 21.8 & - & - & & $\begin{array}{l}\text { F: } 21.2 \\
\text { M: } 13.5\end{array}$ & 18.2 & 12.8 & - & - & - \\
\hline Public event or party & - & - & 4.3 & - & - & $\begin{array}{l}\text { F: } 20 \\
\text { M: } 14\end{array}$ & & 13.6 & - & - & - & - \\
\hline \multicolumn{13}{|l|}{ Type of abuse } \\
\hline Unwanted sexual intercourse & F: 57.1 & $\begin{array}{l}\text { F: } 2.7 \\
\text { M: } 2.8\end{array}$ & M: 0.3 & $\begin{array}{l}\text { F: } 1.7 \\
\text { M: } 3.6\end{array}$ & $\begin{array}{l}\text { F: } 3.1 \\
\text { M: } 3.0\end{array}$ & $\begin{array}{c}\text { F: } 7 \\
\text { M: } 12\end{array}$ & $\begin{array}{l}\text { F: } 10.0 \\
\text { M: } 2.0\end{array}$ & M: 3.5 & $\begin{array}{c}\text { F: } 93 \\
\text { M: } 21.8\end{array}$ & 32.2 & 7.1 & $\begin{array}{l}\text { F: } 8.8 \\
\text { M: } 8.6\end{array}$ \\
\hline
\end{tabular}




\section{Continued}

\begin{tabular}{|c|c|c|c|c|c|c|c|c|c|c|c|}
\hline Fondling/Sexual touching & F: 32.7 & - & - & $\begin{array}{l}\text { F: } 2.5 \\
\text { M: } 3.0\end{array}$ & $\begin{array}{l}\text { F: } 13.8 \\
\text { M: } 14.8\end{array}$ & $\begin{array}{l}F: 24.7 \\
M: 10.9\end{array}$ & - & $\begin{array}{l}\text { F: } 14.4 \\
\text { M: } 23.6\end{array}$ & 62.4 & 60.0 & 18.3 \\
\hline Exposure to pornography & F: 28.7 & - & - & $\begin{array}{l}\text { F: } 2.7 \\
\text { M: } 6.1\end{array}$ & $\begin{array}{c}\text { F: } 12.4 \\
\text { M: } 36.9\end{array}$ & & - & - & 55.9 & - & $F: 2.2$ \\
\hline Anal penetration & - & - & - & - & - & & - & $\begin{array}{l}\text { F: } 1.4 \\
\text { M: } 60\end{array}$ & - & - & $\begin{array}{l}\text { F: } 2.2 \\
\text { M: } 4.6\end{array}$ \\
\hline Kissing & - & - & - & - & - & & - & & 64.5 & 13.3 & 12.9 \\
\hline
\end{tabular}

Table 4. Studies on child sexual abuse in Asia and Africa reporting proportion of victims at certain age.

\begin{tabular}{|c|c|c|}
\hline & Country & Proportion of abused children at certain age \\
\hline \multicolumn{3}{|l|}{ Asia } \\
\hline Luo et al., 2008 & China & $\begin{array}{l}2.0 \% \text { of females and } 1.6 \% \text { of males experienced contact SA between ages } 2-11 \text { years; } 1.1 \% \text { of females and } \\
3.3 \% \text { of males experienced contact SA between ages } 12-13 \text { years }\end{array}$ \\
\hline Daral et al., 2016 & India & $\begin{array}{l}59.3 \% \text { of victims experienced first CSA between the ages of } 14-16 \text { years; } 28.9 \% \text { of victims experienced first } \\
\text { CSA between the ages of } 10-13 \text { years; } 11.8 \% \text { of victims experienced first CSA between the ages of } 17-19\end{array}$ \\
\hline UNICEF, 2018a & Lao & $22 \%$ experienced sexual violence prior to age $13 ; 25 \%$ between the ages $14-15 ; 53 \%$ between the ages $16-17$ \\
\hline Sumner et al., 2016 & Cambodia & $59.1 \%$ of males experienced first episode of CSA at 10 years or below \\
\hline $\begin{array}{l}\text { Fernando \& } \\
\text { Karunasekera, } 2009\end{array}$ & Sri Lanka & $12.5 \%$ of victims experienced fondling of their genitals when they were 11 years of age (by a known person) \\
\hline & & $3 \%$ of victims were sexually assaulted by an adult when they were 11.6 years of age \\
\hline \multicolumn{3}{|l|}{ Africa } \\
\hline McCrann et al. (2006) & Tanzania & $\begin{array}{l}10.2 \% \text { of all abuse happened during pre-pubertal; } 1 \% \text { of victims experienced unwanted sexual intercourse } \\
\text { before age } 13\end{array}$ \\
\hline David et al., 2018 & Nigeria & $\begin{array}{l}45.2 \% \text { reported first abuse experience between } 9-12 \text { years of age; } 16.1 \% \text { experienced first sexual abuse } 5-8 \\
\text { years of age; } 17.2 \% \text { reported first abuse experiences at age } 13 \text { \& above }\end{array}$ \\
\hline Sumner et al., 2016 & Kenya & $13.7 \%$ of victims (males) experienced their first episode of CSA when they were 10 years and below \\
\hline Reza et al., 2009 & Swaziland & $\begin{array}{l}11.9 \% \text { of victims experienced first incidents of sexual violence }<13 \text { years of age; } 88.1 \% \text { of victims } \\
\text { experienced first incidents of sexual violence between } 13 \text { and } 17 \text { years of age }\end{array}$ \\
\hline Birdthistle et al., 2011 & Zimbabwe & $60 \%$ of female victims and $93 \%$ of male victims were classified as "pre-pubertal" at clinical presentation \\
\hline
\end{tabular}

\section{Discussion}

This literature review examined prevalence and patterns of CSA in Asia and Africa as reported in 46 papers published between 2000 and 2018. As it was expected the prevalence of child sexual abuse in both regions varies greatly which may well be explained to be due to different methodological approaches as shown in Figure 2. Asian males have higher rates of sexual victimization than females while in Africa majority of studies reported higher rates of abuse among girls compared to boys.

The higher rates of victimization of boys in Asia is consistent with findings of 


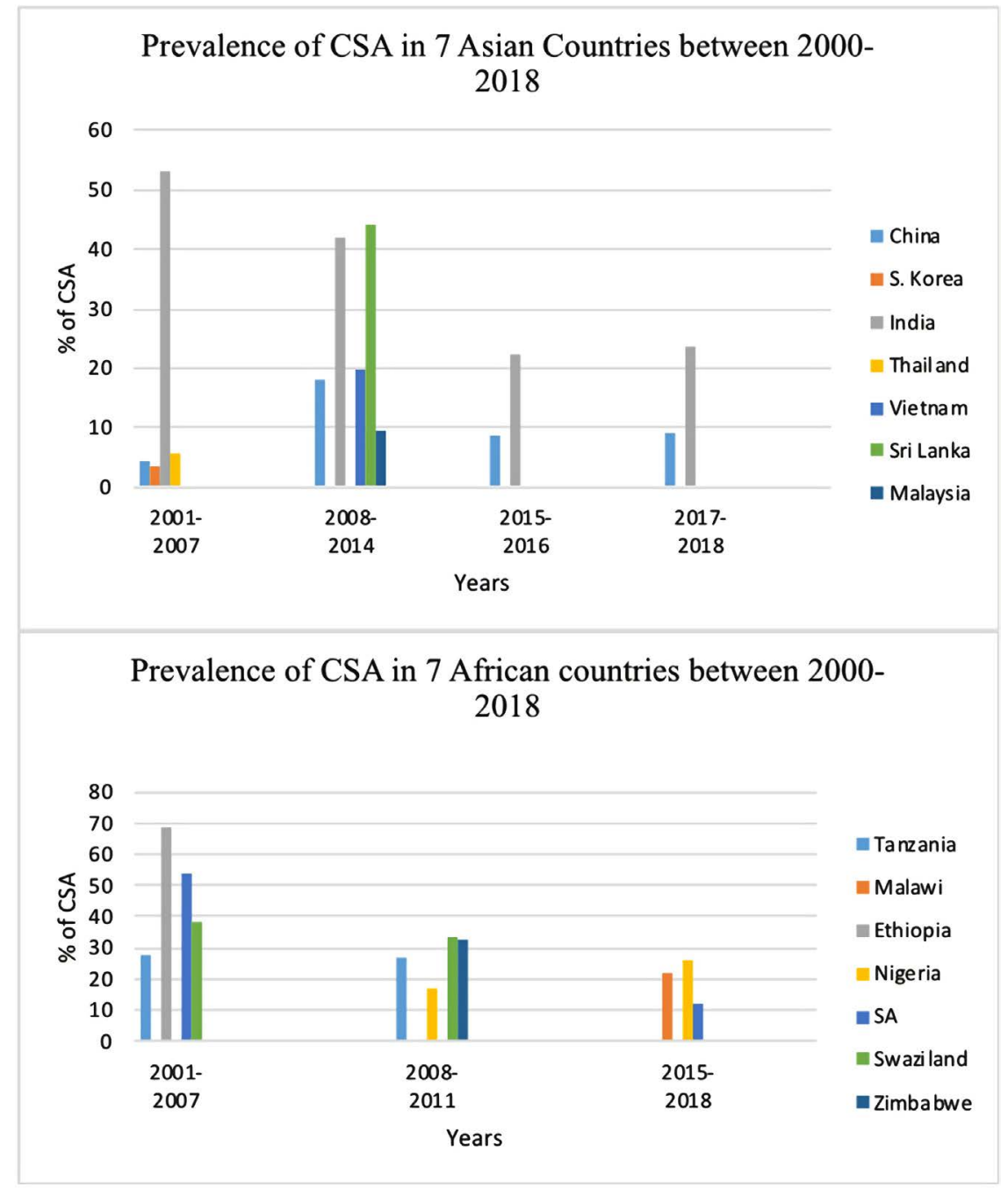

Figure 2. Percentage of abuse in Asia and Africa in various year cohorts and studies. Note: The figures above comprise studies which applied different definition and methodological approach to CSA.

other researchers who compared patterns of victimization of males and females in the west and those in Asia. It was reported in one study that girls from western countries are two to three times more likely than boys to report unwanted sexual experiences before age 18, while studies in Asian countries find gender equivalence or higher rates of sexual victimization of boys (Choo et al., 2011). Luo and colleagues 2007 found higher rates of abuse among Chinese men (5.1\%) compared to women $(3.3 \%)$ and commented that the observed pattern contrasted with the typical pattern in the west which has a higher prevalence for women than for men and found that the prevalence for Chinese men was within the $3 \%-10 \%$ prevalence for men in the west and that the prevalence for Chinese women was far lower than the typical 10\% - 20\% for women in the west (Luo et al., 2008). This is also the case in some studies in India were young boys were found to have similar and sometimes higher prevalence of CSA as girls (Choudhry et al., 2018). The culture within Asian communities may explain this rather 
untypical pattern. One possible explanation with regard to lower prevalence among Chinese women is that, the Chinese cultural traditions shielded children, particularly girls from childhood sexual contact. However, it may also be due to significant underreporting by women to preserve the integrity of the child and family (Luo et al., 2008). Studies in India and in South Asia reported the taboo and cultural and familial stigma around CSA as preventing the disclosure of abuse experiences among girls (Singh et al., 2014). The higher rates of sexual abuse in Africa has been associated with several factors including rapid social change, the myth surrounding HIV cure and avoidance strategy and the patriarchal nature of the society (Lalor, 2004).

The study also found that children in all age groups stand the risk of being sexually victimized. Majority of studies in Africa have reported higher rates of pre-pubertal sexual abuse. A study in South Africa reported similar scenario which showed that sexual abuse of pre-pubertal children occurs with unacceptable frequency (Richter et al., 2004). However, a study in India, 2016 found that the odds of sexual abuse increased in the mid and late adolescence (Daral et al., 2016). This trend of high victimization of very young children in Africa particularly girls is associated with the myth surrounding HIV cure, avoidance strategy and good fortune-"virgin myth" (Lalor, 2004). There is a wide belief in Africa that having sex with a virgin girl cures Sexually Transmitted Diseases including HIV but also African men hold that sex with a young girl helps them avoid contracting HIV since a virgin is most likely to be clean. Moreover, there is a belief that sex with a virgin may bring good fortune in life (McCrann et al., 2006). In addition, poverty, being orphan and position of girls and women in the society are strongly associated with the risk of CSA.

Most perpetrators of sexual abuse are well known to the victim before the onset of the abuse. Majority of studies in Africa have shown friend and neighbours to be the most common perpetrators while relatives were most cited in Asian studies. This observation is supported by a number of other authors that CSA is usually perpetrated by someone known to the child (David et al., 2018). Finally, CSA can take place in a variety of setting, at home, school, open place, in the public event and neighborhood. Majority of studies across the world have found similar pattern (David et al., 2018; Lalor, 2004). This shows children are vulnerable everywhere hence coordinated approach is crucial in addressing CSA.

\section{Conclusion}

There is no doubt that child sexual abuse is still the major public health, social and human rights problem in the world today. The observed patterns and characteristics indicate some similarities and variation across Asia and Africa. The study found both males and females in different age cohorts of adolescents to be at significantly high risk of being sexually abused. In both regions majority of perpetrators of CSA are well known to the victims. This review also highlights the devastating effect of armed-conflict on children vulnerability. The CSA fig- 
ures in DRC indicate the magnitude of the problem and therefore local, national and international community should put more deliberate effort to protect this high-risk group. Parents, children and the community should be educated and made aware of the problem of CSA. Child-friendly judicial system and effective legislations are crucial in facilitating reporting and handling of abuse cases. Governments should engage key stakeholders in addressing CSA. Future research should focus more on population-based studies and using comparable methodology.

\section{Conflicts of Interest}

The authors declare no conflicts of interest regarding the publication of this paper.

\section{References}

Barth, J., Bermetz, L., Heim, E., Trelle, S., \& Tonia, T. (2013). The Current Prevalence of Child Sexual Abuse Worldwide: A Systematic Review and Meta-Analysis. International Journal of Public Health, 58, 469-483. https://doi.org/10.1007/s00038-012-0426-1

Birdthistle, I. J., Floyd, S., Mwanasa, S., Nyagadza, A., Gwiza, E., \& Glynn, J. R. (2011). Child Sexual Abuse and Links to HIV and Orphanhood in Urban Zimbabwe. Journal of Epidemiology and Community Health, 65, 1075-1082. https://doi.org/10.1136/jech.2009.094359

Chan, K. L., Yan, E., Brownridge, D. A., \& Ip, P. (2013). Associating Child Sexual Abuse with Child Victimization in China. The Journal of Pediatrics, 162, 1028-1034. https://doi.org/10.1016/j.jpeds.2012.10.054

Choo, W.-Y., Dunne, M. P., Marret, M. J., Fleming, M., \& Wong, Y.-L. (2011). Victimization Experiences of Adolescents in Malaysia. Journal of Adolescent Health, 49, 627-634. https://doi.org/10.1016/j.jadohealth.2011.04.020

Choudhry, V., Dayal, R., Pillai, D., Kalokhe, A. S., Beier, K., \& Patel, V. (2018). Child Sexual Abuse in India: A Systematic Review. PLoS ONE, 13, e0205086. https://doi.org/10.1371/journal.pone.0205086

Daral, S., Khokhar, A., \& Pradhan, S. (2016). Prevalence and Determinants of Child Maltreatment among School-Going Adolescent Girls in a Semi-Urban Area of Delhi, India. Journal of Tropical Pediatrics, 62, 227-240. https://doi.org/10.1093/tropej/fmv106

David, N., Ezechi, O., Wapmuk, A., Gbajabiamila, T., Ohihoin, A., Herbertson, E., \& Odeyemi, K. (2018). Child Sexual Abuse and Disclosure in South Western Nigeria: A Community Based Study. African Health Sciences, 18, 199-208.

https://doi.org/10.4314/ahs.v18i2.2

Fang, X., Fry, D. A., Brown, D. S., Mercy, J. A., Dunne, M. P., Butchart, A. R., Corso, P. S., Maynzyuk, K., Dzhygyr, Y., Chen, Y., McCoy, A., \& Swales, D. M. (2015). The Burden of Child Maltreatment in the East Asia and Pacific Region. Child Abuse \& Neglect, 42, 146-162. https://doi.org/10.1016/j.chiabu.2015.02.012

Fernando, A. D., \& Karunasekera, W. (2009). Juvenile Victimisation in a Group of Young Sri Lankan Adults. Ceylon Medical Journal, 54, 80-84. https://doi.org/10.4038/cmj.v54i3.1200

Finkelhor, D. (1994). The International Epidemiology of Child Sexual Abuse. Child Abuse \& Neglect, 18, 409-417. https://doi.org/10.1016/0145-2134(94)90026-4

Fu, H., Feng, T., Qin, J., Wang, T., Wu, X., Cai, Y., Lan, L., \& Yang, T. (2018). Reported 
Prevalence of Childhood Maltreatment among Chinese College Students: A Systematic Review and Meta-Analysis. PLoS One, 13, e0205808.

https://doi.org/10.1371/journal.pone.0205808

Hillis, S., Mercy, J., Amobi, A., \& Kress, H. (2016). Global Prevalence of Past-Year Violence against Children: A Systematic Review and Minimum Estimates. Pediatrics, 137, e20154079. https://doi.org/10.1542/peds.2015-4079

Ji, K., Finkelhor, D., \& Dunne, M. (2013). Child Sexual Abuse in China: A Meta-Analysis of 27 Studies. Child Abuse \& Neglect, 37, 613-622. https://doi.org/10.1016/j.chiabu.2013.03.008

Jirapramukpitak, T., Prince, M., \& Harpham, T. (2005). The Experience of Abuse and Mental Health in the Young Thai Population A Preliminary Survey. Social Psychiatry and Psychiatric Epidemiology, 40, 955-963. https://doi.org/10.1007/s00127-005-0983-1

Kenny, M. C., \& McEachern, A. G. (2000). Racial, Ethnic, and Cultural Factors of Childhood Sexual Abuse: A Selected Review of the Literature. Clinical Psychology Review, 20, 905-922. https://doi.org/10.1016/S0272-7358(99)00022-7

Kim, H.-S., \& Kim, H.-S. (2005). Incestuous Experience among Korean Adolescents: Prevalence, Family Problems, Perceived Family Dynamics, and Psychological Characteristics. Public Health Nursing, 22, 472-482. https://doi.org/10.1111/j.0737-1209.2005.220604.x

Kumar, M. T., Kumar, S., Singh, S. P., \& Kar, N. (2017). Prevalence of Child Abuse in School Environment in Kerala, India: An ICAST-CI Based Survey. Child Abuse \& Neglect, 70, 356-363. https://doi.org/10.1016/j.chiabu.2017.06.025

Kunnuji, M. O. N., \& Esiet, A. (2015). Prevalence and Correlates of Sexual Abuse among Female Out-of-School Adolescents in Iwaya Community, Lagos State, Nigeria. African Journal of Reproductive Health, 19, 82-90.

Lalor, K. (2004). Child Sexual Abuse in Sub-Saharan Africa: A Literature Review. Child Abuse \& Neglect, 28, 439-460. https://doi.org/10.1016/j.chiabu.2003.07.005

Lin, D., Li, X., Fan, X., \& Fang, X. (2011). Child Sexual Abuse and Its Relationship with Health Risk Behaviors among Rural Children and Adolescents in Hunan, China. Child Abuse \& Neglect, 35, 680-687. https://doi.org/10.1016/j.chiabu.2011.05.006

Luo, Y., Parish, W. L., \& Laumann, E. O. (2008). A Population-Based Study of Childhood Sexual Contact in China: Prevalence and Long-Term Consequences. Child Abuse \& Neglect, 32, 721-731. https://doi.org/10.1016/j.chiabu.2007.10.005

Ma, Y. (2018). Prevalence of Childhood Sexual Abuse in China: A Meta-Analysis. Journal of Child Sexual Abuse, 27, 107-121. https://doi.org/10.1080/10538712.2018.1425944

Madu, S. N., \& Peltzer, K. (2001). Prevalence and Patterns of Child Sexual Abuse and Victim-Perpetrator Relationship among Secondary School Students in the Northern Province (South Africa). Archives of Sexual Behavior, 30, 311-321. https://doi.org/10.1023/A:1002704331364

Martin, E. K., \& Silverstone, P. H. (2013). How Much Child Sexual Abuse Is "Below the Surface," and Can We Help Adults Identify It Early? Front Psychiatry, 4, 58. https://doi.org/10.3389/fpsyt.2013.00058

McCrann, D., Lalor, K., \& Katabaro, J. K. (2006). Childhood Sexual Abuse among University Students in Tanzania. Child Abuse \& Neglect, 30, 1343-1351. https://doi.org/10.1016/j.chiabu.2006.05.009

Miles, G. M. (2000). “Children Don't Do Sex with Adults for Pleasure”: Sri Lankan Children's Views on Sex and Sexual Exploitation. Child Abuse \& Neglect, 24, 995-1003. https://doi.org/10.1016/S0145-2134(00)00152-6 
Ministry of Women and Child Development (MWCD), Government of India (2007). Study on Child Abuse 2007. Contemporary Education Dialogue, 5, 117-120. https://doi.org/10.1177/0973184913411162

Nelson, B. D., Collins, L., VanRooyen, M. J., Joyce, N., Mukwege, D., \& Bartels, S. (2011). Impact of Sexual Violence on Children in the Eastern Democratic Republic of Congo. Medicine, Conflict and Survival, 27, 211-225. https://doi.org/10.1080/13623699.2011.645148

Nguyen, H. T., Dunne, M. P., \& Le, A. V. (2010). Multiple Types of Child Maltreatment and Adolescent Mental Health in Viet Nam. Bulletin of the World Health Organization, 88, 22-30. https://doi.org/10.2471/BLT.08-060061

Olley, B. O. (2008). Child Sexual Abuse, Harmful Alcohol Use and Age as Determinants of Sexual Risk Behaviours among Freshmen in a Nigerian University. African Journal of Reproductive Health, 12, 75-88.

Pan, S.-M. (2007). Prevalence of Sexual Abuse of People with Intellectual Disabilities in Taiwan. Intellectual and Developmental Disabilities, 45, 373-379. https://doi.org/10.1352/1934-9556(2007)45[373:POSAOP]2.0.CO;2

Pereda, N., Guilera, G., Forns, M., \& Gómez-Benito, J. (2009). The International Epidemiology of Child Sexual Abuse: A Continuation of Finkelhor (1994). Child Abuse \& Neglect, 33, 331-342. https://doi.org/10.1016/j.chiabu.2008.07.007

Reza, A., Breiding, M. J., Gulaid, J., Mercy, J. A., Blanton, C., Mthethwa, Z., Bamrah, S., Dahlberg, L. L., \& Anderson, M. (2009). Sexual Violence and Its Health Consequences for Female Children in Swaziland: A Cluster Survey Study. The Lancet, 373, 1966-1972. https://doi.org/10.1016/S0140-6736(09)60247-6

Richter, L. M., Richter, L., Dawes, A., \& Higson-Smith, C. (2004). Sexual Abuse of Young Children in Southern Africa. HSRC Press.

Richter, L., Komarek, A., Desmond, C., Celentano, D., Morin, S., Sweat, M., Chariyalertsak, S., Chingono, A., Gray, G., Mbwambo, J., \& Coates, T. (2014). Reported Physical and Sexual Abuse in Childhood and Adult HIV Risk Behaviour in Three African Countries: Findings from Project Accept (HPTN-043). AIDS and Behavior, 18, 381-389. https://doi.org/10.1007/s10461-013-0439-7

Singh, M. M., Parsekar, S. S., \& Nair, S. N. (2014). An Epidemiological Overview of Child Sexual Abuse. Journal of Family Medicine and Primary Care, 3, 430-435. https://doi.org/10.4103/2249-4863.148139

Stoltenborgh, M., van IJzendoorn, M. H., Euser, E. M., \& Bakermans-Kranenburg, M. J. (2011). A Global Perspective on Child Sexual Abuse: Meta-Analysis of Prevalence around the World. Child Maltreatment, 16, 79-101. https://doi.org/10.1177/1077559511403920

Sumner, S. A., Mercy, J. A., Buluma, R., Mwangi, M. W., Marcelin, L. H., Kheam, T., Lea, V., Brookmeyer, K., Kress, H., \& Hillis, S. D. (2016). Childhood Sexual Violence against Boys: A Study in 3 Countries. Pediatrics, 137, e20153386.

https://doi.org/10.1542/peds.2015-3386

Sun, Y.-P., Zhang, B., Dong, Z.-J., Yi, M.-J., Sun, D.-F., \& Shi, S.-S. (2008). Psychiatric State of College Students with a History of Childhood Sexual Abuse. World Journal of Pediatrics, 4, 289-294. https://doi.org/10.1007/s12519-008-0052-4

Tang, C. S. (2002). Childhood Experience of Sexual Abuse among Hong Kong Chinese College Students. Child Abuse \& Neglect, 26, 23-37.

https://doi.org/10.1016/S0145-2134(01)00306-4

Tomori, C., McFall, A. M., Srikrishnan, A. K., Mehta, S. H., Nimmagadda, N., Anand, S., Vasudevan, C. K., Solomon, S., Solomon, S. S., \& Celentano, D. D. (2016). The Preva- 
lence and Impact of Childhood Sexual Abuse on HIV-Risk Behaviors among Men Who Have Sex with Men (MSM) in India. BMC Public Health, 16, Article No. 784. https://doi.org/10.1186/s12889-016-3446-6

UNICEF (2007). A National Study on Violence against Children and Young Women in Swaziland. https://www.unicef.org/swaziland/Violence_study_report.pdf

UNICEF (2009). Violence against Children in Tanzania Findings from a National Survey https://www.unicef.org/media/files/VIOLENCE_AGAINST_CHILDREN_IN_TANZA NIA_REPORT.pdf

UNICEF (2013). Violence against Children and Young Women in Malawi, Findings from a National Survey.

UNICEF (2018a) N.C. for M. and C.S.B., the National Violence against Children Survey in Lao PDR. National Commission for Mothers and Children.

UNICEF (2018b). Uganda Violence against Children Survey Findings from a National Survey.

Ward, C. L., Artz, L., Leoschut, L., Kassanjee, R., \& Burton, P. (2018). Sexual Violence against Children in South Africa: A Nationally Representative Cross-Sectional Study of Prevalence and Correlates. The Lancet, 6, e460-e468.

https://doi.org/10.1016/S2214-109X(18)30060-3

Worku, D., Gebremariam, A., \& Jayalakshmi, S. (2006). Child Sexual Abuse and Its Outcomes among High School Students in Southwest Ethiopia. Tropical Doctor, 36, 137-140. https://doi.org/10.1258/004947506777978325

Yen, C.-F., Yang, M.-S., Yang, M.-J., Su, Y.-C., Wang, M.-H., \& Lan, C.-M. (2008). Childhood Physical and Sexual Abuse: Prevalence and Correlates among Adolescents Living in Rural Taiwan. Child Abuse \& Neglect, 32, 429-438.

https://doi.org/10.1016/j.chiabu.2007.06.003

Zhao, Q., Zhao, J., Li, X., Zhao, G., Fang, X., Lin, X., Lin, D., \& Stanton, B. (2011). Childhood Sexual Abuse and Its Relationship with Psychosocial Outcomes among Children Affected by HIV in Rural China. Journal of the Association of Nurses in AIDS Care, 22, 202-214. https://doi.org/10.1016/j.jana.2010.08.004

Zimbabwe National Statistics Agency, U. (2011). National Baseline Survey on Life Experiences of Adolescents Report (NBSLEA).

http://www.togetherforgirls.org/wp-content/uploads/2017/09/2011_Zimbabwe_Nation al-Baseline-Survey.pdf 